\title{
Anticonvulsant Effect of Artemisia capillaris Herba in Mice
}

\author{
Tae Seon Woo', Seo Young Yoon ${ }^{1,5}$, Ike Campomayor dela Peña', Ji Young Choi', Hye Lim Lee', \\ Yoon Jung Choi ${ }^{1}$, Yong Soo Lee ${ }^{2}$, Jong Hoon Ryu ${ }^{3}$, Jae Sue Choi ${ }^{4}$ and Jae Hoon Cheong ${ }^{1, *}$ \\ ${ }^{1}$ Uimyung Research Institute for Neuroscience, Sahmyook University, Seoul 139-742, \\ 2Department of Pharmacology, College of Pharmacy, Duksung Women's University, Seoul 132-714, \\ ${ }^{3}$ Department of Oriental Pharmaceutical Science, College of Pharmacy, Kyung Hee University, Seoul 130-701, \\ ${ }^{4}$ Department of Food Science and Nutrition, College of Fisheries Science, Pukyong National University, Busan 608-739, \\ ${ }^{5}$ Department of Pharmacology, College of Pharmacy, Seoul National University, Seoul 151-742, Republic of Korea
}

\begin{abstract}
In the present study, the anticonvulsant effects of Artemisia capillaris Herba (AC) and its major constituent, esculetin (ECT), were tested and the mechanism studied. Locomotion, Myorelaxation, motor coordination and electroshock seizure experiment were conducted in mice. To identify the anticonvulsant mechanism effect of this drug, chemical-induced seizure in mice and the ionic movement in neuroblastoma cells were also observed. The ethanol extract of AC was orally administered to mice 30 min. prior to testing and ECT was intraperitoneally injected. AC and ECT treatment did not change locomotor activities as well as activities on the rota-rod, which indicates that they did not cause a sedative and myorelaxation effect. AC and ECT treatment increased threshold of convulsion induced by electroshock. AC treatment also inhibited convulsion induced by pentylenetetrazole. In the case of strychnine however, only high dose of $\mathrm{AC}$ treatment inhibited convulsion. $\mathrm{AC}$ and $\mathrm{ECT}$ treatment increased the $\mathrm{Cl}^{-}$influx into the intracellular area in a dose-dependent manner. On the other hand, bicuculline, a GABA antagonist, inhibited the $\mathrm{Cl}^{-}$influx induced by $A C$ and ECT. These results indicate that ECT induces the anticonvulsive effect of AC extract through the GABAergic neuron.
\end{abstract}

Key Words: Artemisia capillaris, Esculetin, Anticonvulsion, Seizure, GABA

\section{INTRODUCTION}

Epilepsy is one of the most common serious neurological conditions, with an annual incidence of 50 people per 100,000 (Poole et al., 2000). Seizures are controlled in nearly $70 \%$ of patients with epilepsy, mostly through drug effects on membrane ion channels or on GABAergic or glutamatergic transmission. However, for the remaining $20-30 \%$ with intractable seizures, recent advances in systemic antiepileptic drug development have had little impact. Refractory epilepsy is associated with considerable medical, social, and psychiatric morbidity and enormous financial costs (Sander, 2003). Thus, despite the beneficial effect of the currently available drugs, there is still a need for broadly acting anticonvulsant drugs possessing multiple mechanisms of action with decreased adverse effect, preferably originated from natural products (Park et al., 2007).

Herbal medicine is one of the most common forms of alternative medicine, and patients generally consider this form of treatment to be both safe and effective (Eisenberg et al.,
1998). Despite increasing interest in alternative medicine use, there are limited data on alternative medicine use by patients with epilepsy (Gidal et al., 1999). Therefore, we investigated several plants to discover whether they have anticonvulsant activities.

As one of the famous traditional Chinese medicine, Artemisia capillaris Herba (AC) is listed officially in the Chinese pharmacopoeia and used as a choleretic, anti-inflammatory and diuretic agent in the treatment of epidemic hepatitis (Tang and Eisenbrand1992). Esculetin (ECT), which is main constituent of $\mathrm{AC}$, has multiple pharmacological activities including the inhibition of xanthine oxidase activity (Egan et al., 1990), platelet aggregation (Okada et al., 1995) and antioxidant activity (Paya et al. 1992; Lin et al. 2000). Although AC and ECT have various biological effects, their anticonvulsant effects have not been reported.

In the present study, we examined the anticonvulsant effect of the $70 \%$ ethanol extract of AC and its mechanism. The objective of this study was to evaluate the possibility of $A C$ as an anticonvulsant drug and to find out which constituent ex- www.biomolther.org

Open Access DOI: 10.4062/biomolther.2011.19.3.342

pISSN: 1976-9148 elSSN: 2005-4483

Copyright $\odot 2011$ The Korean Society of Applied Pharmacology
Received Apr 30, 2011 Revised Jul 27, 2011 Accepted Jul 18, 2011

*Corresponding Author

Tel: +82-2-3399-1605, Fax: +82-2-3399-1619 
erts this activity. First, behavioral tests, electroshock seizure, chemical induced seizure were studied in vivo in ICR mice. Secondly, influx of $\mathrm{Cl}^{-}$was studied in vitro using neuroblastoma cells.

\section{MATERIALS AND METHODS}

\section{Materials}

$70 \%$ ethanol extract of AC was supplied by the National Center for Standardization of Herbal Medicine. ECT was purchased from Wako Pure Chemical Industries (Japan). Bicuculline, diazepam and other materials were purchased from Sigma-Aldrich Co. (St. Louis, Mo, USA). N-(6-methoxyquinolyl) acetoethylester (MQAE) was purchased from Invitrogen Co. (Carlsbad, USA). $70 \%$ ethanol extract of Artemisia capillaris, diazepam, strychnine and pentylenetetrazol (PTZ) were dissolved in sterile distilled water before injection. AC was orally administered in a doses of 50,100, 200, $400 \mathrm{mg} / \mathrm{kg}$ and ECT was intraperitoneally injected in doses of 1,2 and $5 \mathrm{mg} / \mathrm{kg}$. $5 \mathrm{mg} / \mathrm{kg}$ of diazepam was intraperitoneally injected to mice to serve the positive control group. Animals of the negative control group were administered saline. Bicuculline was dissolved in dimethyl sulfoxide (DMSO) and the maximum concentration of DMSO was $0.1 \%$. Cells were cultured in MEM (Gibco BRL, Rockville, MD) supplemented with $10 \%$ fatal bovine serum(FBS) and $5 \% \mathrm{CO}_{2}$ at $37^{\circ} \mathrm{C}$.

\section{Animals and treatments}

The male ICR mice (20-25 g) used in this study were obtained from Hanlim Laboratory Animals Co. (Hwaseong, Korea). They were housed in animal room which was maintained at temperature $\left(22 \pm 2^{\circ} \mathrm{C}\right)$ and humidity $(55 \pm 5 \%)$ under a 12/12-hr light/dark cycle with lights on from 7:00 AM. Food and water were available ad libitum. All animals were acclimated to their home cages for at least 6 days before testing. The experimental groups, consisting of 8-10 animals per drug and dose, were chosen by means of a randomized schedule and all mice were used only once. All tests took place between 10:00 and 16:00 h. Animal treatment and maintenance were carried out in accordance with the Principles of Laboratory Animal Care (NIH publication No. 85-23 revised 1985) and the Animal Care and Use Guidelines of Sahmyook University, Korea.

\section{Locomotor activity}

Computerized EthoVision system (Noldus IT b.v., Netherlands) was used to evaluate changes in locomotor activity. The observation apparatus consisted of five plastic boxes $(42 \times 42 \mathrm{~cm})$ with a field bordered by $42-\mathrm{cm}$-high sidewalls. The total distance moved, total movement time, and total turn angle degree were monitored for 10 min after administration (Noldus et al., 2001; Kim et al., 2003).

\section{Rota-rod test}

The rota-rod test was used to assess whether materials caused myorelaxation or gross motor impairment in the animals. Twenty-four hours before the experiment, all mice were habituated to running in a rota-rod at a speed of $36 \mathrm{rpm}$ for 3 minutes. The latency to fall and falling frequency were recorded $30 \mathrm{~min}$ after administration (Farkas et al., 2005; Lee et al., 2006).

\section{Measurement of electroshock seizure threshold}

Seizure was evoked by constant current stimulator and the resulting seizure was determined by overt hindlimb extension. To determine the electroshock seizure threshold, convulsive current $50\left(\mathrm{CC}_{50}\right)$ which elicits convulsion in $50 \%$ of animals was calculated by a 'staircase' procedure (Browning et al., 1990). Individual animals was treated with electroshocks of 1 second stimulus duration to determine the current-convulsion relationship. If an animal showed convulsion, the next animal was given with $3 \mathrm{~mA}$ decrements in current intensity. If an animal did not show convulsion, the next animal was given with $3 \mathrm{~mA}$ increments in current intensity. In this way, the currentconvulsion relationship was generated and $\mathrm{CC}_{50}$ value was determined by Litchfield-Wilcoxons II method (Litchfield and Wilcoxon, 1949). For each treatment group, 20-30 pups were prepared and the animals were sacrificed right after the determination of the electroshock seizure threshold.

\section{Test for anticonvulsant potency (PTZ model)}

The different experimental groups of mice ( $n=10 /$ group) orally treated with $50 \mathrm{mg} / \mathrm{kg}$ and $100 \mathrm{mg} / \mathrm{kg}$ of AC were challenged with PTZ (70 mg/kg, i.p.) $30 \mathrm{~min}$. after the administration of AC (Novack et al., 2005; Obniska et al., 1978). Control group received saline. The percentage of seizure response induced by PTZ in mice was recorded and compared with the respective control group.

\section{Test for anticonvulsant potency (strychnine model)}

The different experimental groups of mice ( $n=10 /$ group) treated with $100 \mathrm{mg} / \mathrm{kg}, 200 \mathrm{mg} / \mathrm{kg}$ and $400 \mathrm{mg} / \mathrm{kg}$ of AC were challenged with strychnine $(1 \mathrm{mg} / \mathrm{kg}$, i.p.) $30 \mathrm{~min}$. after the administration of AC (Ngo Bum et al., 2001). Control group received saline. The percentage of seizure response induced by strychnine in mice was recorded and compared with the respective control group.

\section{Intracellular $\mathrm{Cl}^{-}$measurement assay}

Relative changes in intracellular $\mathrm{Cl}^{-}$concentration $\left(\left[\mathrm{Cl}^{-}\right] \mathrm{i}\right)$ in SH-SY5Y human neuroblastoma cells were monitored using the $\mathrm{Cl}^{-}$-sensitive indicator, $\mathrm{N}$-(6-methoxyquinolyl) acetoetylester (MQAE), developed by Verkman et al. (1989). Experiments were performed, as described by West and Molly (1996). Briefly, cells were washed twice and resuspended at a concentration of $4 \times 10^{5}$ cells $/ \mathrm{ml}$ in Hank's solution. For loading MQAE into the cells, cells were incubated with the dye overnight at a final concentration of $5 \mathrm{mM}$ at room temperature. Fluorescence (excitation wavelength set at $365 \mathrm{~nm}$ and the emission wavelength at $450 \mathrm{~nm}$ ) was monitored in a well-stirred cuvette. Experiments were performed at room temperature to minimize fluorescent dye loss. Data are presented as relative fluorescence $\mathrm{F} / \mathrm{FO}$, where $\mathrm{F} 0$ is the fluorescence without $\mathrm{Cl}^{-}$ ions and $F$ is the fluorescence as a function of time. The $F /$ $\mathrm{F} 0$ values are directly proportional to $\left[\mathrm{Cl}^{-}\right] \mathrm{i}$. All fluorescence values were corrected for background fluorescence which was separately determined using a HEPES-buffered KSCN solution containing $5 \mu \mathrm{M}$ valinomycin to maximally quench the MQAE ion-selective signal (Shumaker et al., 1999). In separate experiments the $\mathrm{FO}$ value was determined by bathing the cells with $\mathrm{Cl}^{-}$-free $(\mathrm{KNO} 3)$ solution containing $10 \mathrm{mM}$ tributyltin and $10 \mathrm{mM}$ nigericin. 


\section{Statistical analysis}

Data were expressed as the mean \pm S.E.M. For statistical evaluation of data, one-way ANOVA was used. When statistically significant differences were found, Newman-Keul's test was used as a post-hoc test to determine the statistical differences between groups. Differences were considered statistically significant when $p<0.05$.

\section{RESULTS}

\section{Locomotor activity}

Locomotor activities were determined based on the total distance moved and the duration of movement. Fig. 1 and Fig. 2 show that AC and ECT did not change the locomotor activity while diazepam significantly decreased locomotor activity in mice.

\section{Rota-rod test}

Motor coordination was evaluated by rota-rod test. Fig. 3 and Fig. 4 show that AC and ECT did not change the running time and falling frequency on the rota-rod. Diazepam, however, significantly decreased running time and increased falling frequency on the rota-rod.

\section{Measurement of electroshock seizure threshold}

The effects of AC and ECT on the electroshock seizure threshold are shown in Fig. 5. To determine the electroshock seizure threshold, we calculated the convulsive current 50 $\left(\mathrm{CC}_{50}\right)$, which elicits convulsion in $50 \%$ of animals. Electro-
A.

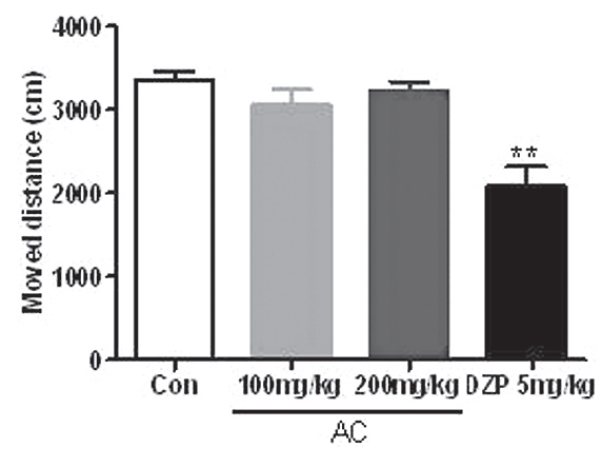

A.

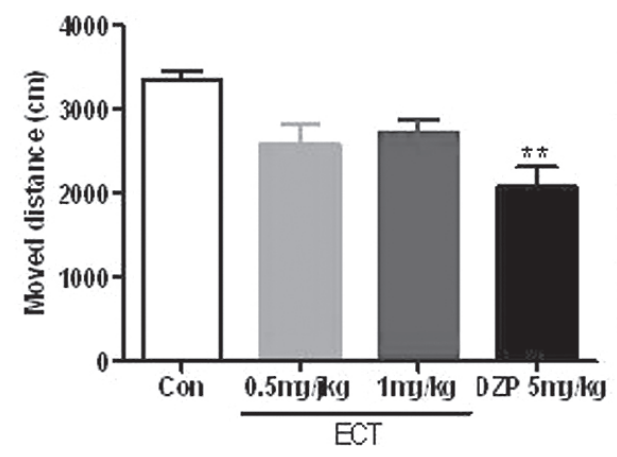

A.

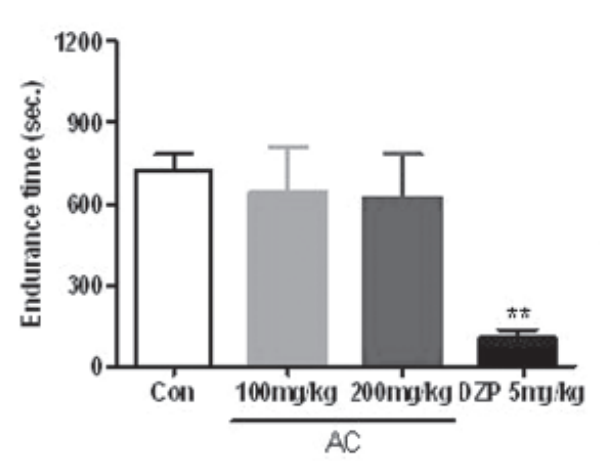

B.

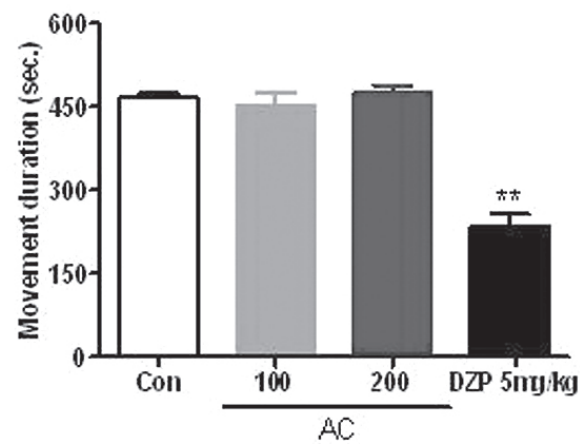

B.

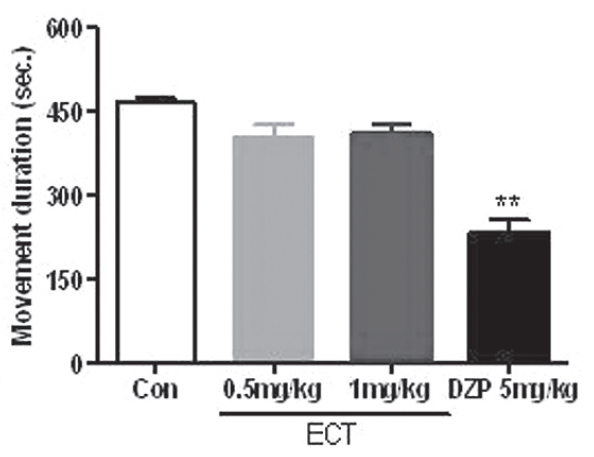

B.

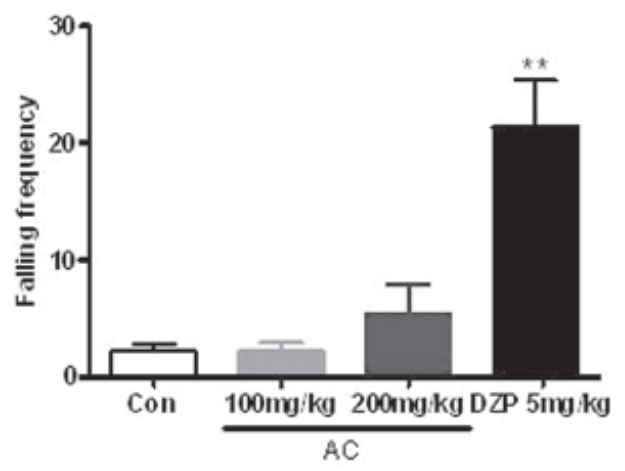

Fig. 1. Effects of $A C$ on Locomotor activity in mice $(n=9-10)$. (A) Each bar represents the mean \pm S.E.M of the moved distance in $\mathrm{AC}$ treatment for 10 minutes. (B) Each bar represents the mean \pm S.E.M of the movement duration in $A C$ treatment for 10 minutes $\left({ }^{* *} p<0.01\right.$ compared to control group).

Fig. 2. Effects of ECT on Locomotor activity in mice (n=9-10). (A) Each bar represents the mean \pm S.E.M of the moved distance in AC treatment for 10 minutes. (B) Each bar represents the mean \pm S.E.M of the movement duration in $A C$ treatment for 10 minutes ( ${ }^{* *} p<0.01$ compared to control group).
Fig. 3. Effects of $A C$ on activity on the rotating rod in mice $(n=9-10)$. (A) Each bar represents the mean \pm S.E.M of endurance time on the rotating rod. (B) Each bar represents the mean \pm S.E.M of falling frequency from rotating rod $\left({ }^{* *} p<0.01\right.$ compared control group). 

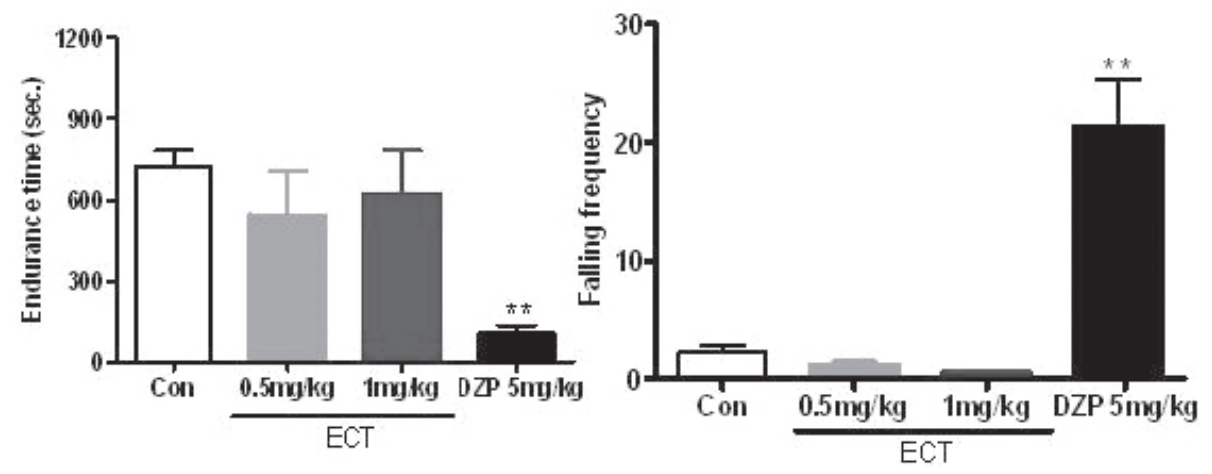

Fig. 4. Effects of ECT on activity on the rotating rod in mice $(n=9-10)$. (A) Each bar represents the mean \pm S.E.M of endurance time on the rotating rod. (B) Each bar represents the mean \pm S.E.M of falling frequency from rotating rod $\left({ }^{* *} p<0.01\right.$ compared control group).

A.

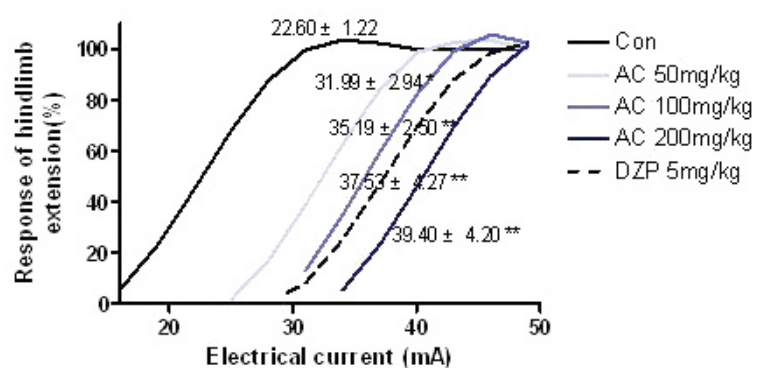

B.

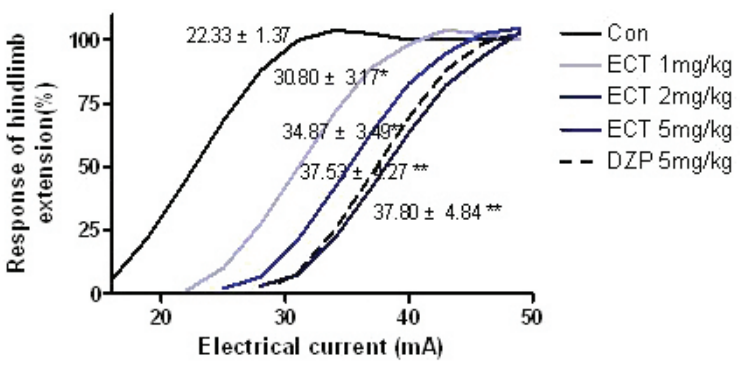

Fig. 5. Effects of $A C$ and ECT on seizure induced by electroshock in mice. Each number on the graph represents $C C_{50} \pm 95 \%$ confidence intervals $\left({ }^{*} p<0.05{ }^{* *} p<0.01\right.$ compared to control group).

shock seizure thresholds of the AC-treated mice were significantly higher than those of the control group. $\mathrm{CC}_{50}$ of the AC-treated mice increased in a dose-dependent manner. The $\mathrm{CC}_{50}$ of the 100 and $200 \mathrm{mg} / \mathrm{kg}$ of AC-treated mice were 35.19 \pm 2.50 and $39.40 \pm 4.20 \mathrm{~mA}$, respectively, and the $\mathrm{CC}_{50}$ of the diazepam-treated group was $37.53 \pm 4.27 \mathrm{~mA}$. The $\mathrm{CC}_{50}$ of the $200 \mathrm{mg} / \mathrm{kg} \mathrm{AC}$ group was significantly higher than that of the diazepam group. ECT treatment also significantly increased electroshock seizure thresholds. The $\mathrm{CC}_{50}$ of the $1 \mathrm{mg} / \mathrm{kg}$ and $2 \mathrm{mg} / \mathrm{kg}$ of ECT treatment were $30.80 \pm 3.17$ and $34.87 \pm 3.49$. The $\mathrm{CC}_{50} 5 \mathrm{mg} / \mathrm{kg}$ of ECT treatment was $37.80 \pm 4.84$ which is higher than that of the same dose of the diazepam treated group.

\section{Test for anticonvulsant potency in PTZ or strychnine model}

Fig. 6 shows that administration of AC decreased the percentage of seizure response induced by PTZ in a dose-dependent manner. However, in Fig. 6, only $400 \mathrm{mg} / \mathrm{kg} \mathrm{AC}$ treat-

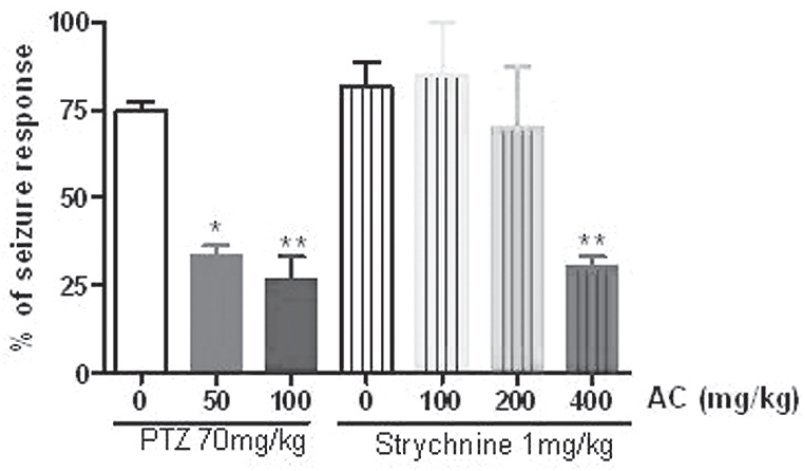

Fig. 6. Effects of $A C$ on seizure induced by chemicals in mice. Each bar represents mean \pm SEM of seizure response $\%\left({ }^{\star} p<0.05\right.$, ${ }^{* *} p<0.01$ compared to control group)

ment significantly change the percentage of seizure response induced by $1 \mathrm{mg} / \mathrm{kg}$ of strychnine.

\section{Intracellular $\mathrm{Cl}^{-}$measurement assay}

Fig. 7 and Fig. 8 show the electrophysiological exchange induced by $A C$ and ECT treatment. $A C$ and ECT treatment increased $\mathrm{Cl}^{-}$influx into the intracellular area in a dose-dependent manner. Conversely, bicuculiline inhibited the $\mathrm{Cl}^{-}$influx induced by AC and ECT treatment.

\section{DISCUSSION}

In the present study, we found out that ethanol extract of $A C$ has significant anticonvulsant activity in both electroshock and PTZ seizure models. Unlike diazepam, AC (100 and 200 $\mathrm{mg} / \mathrm{kg}$ ) did not change the locomotor activity and running time on the rota-rod which indicates that it does not cause sedation and myorelaxation. Such difference between AC and diazepam is beneficial considering that sedation is a common side effect of some GABAergic neuronal anticonvulsnats. ECT, one of the major compounds in $A C$, exerts anticonvulsant activity similar to that of $A C$, which indicates that the effect of $A C$ is due to ECT.

AC significantly decreased seizure response induced by electroshock and PTZ but did not decrease seizure response induced by strychnine except at its highest dose $(400 \mathrm{mg} /$ 
A.

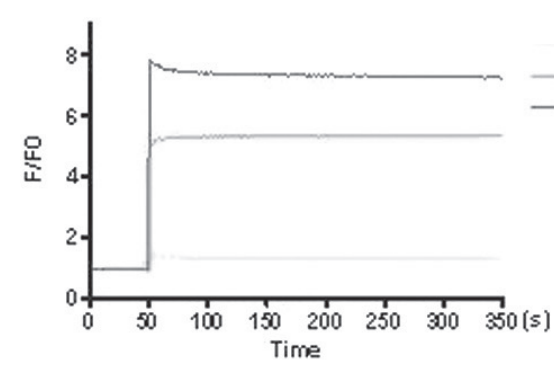

B.

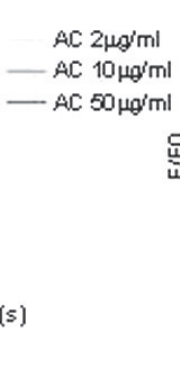

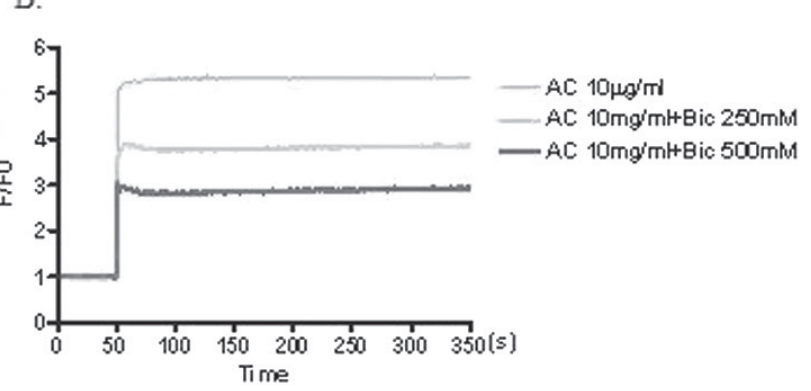

Fig. 7. Effects of $\mathrm{AC}$ on [Cl] in neuroblastoma cells. Fluorescence was monitored in the excitation wavelength at $365 \mathrm{~nm}$ and the emission wavelength at $450 \mathrm{~nm}$ using the $\mathrm{Cl}^{-}$-sensitive indicator, $\mathrm{N}$-(6-methoxyquinolyl) acetoetylester (MQAE) Contents of influx $\mathrm{Cl}^{-}$ion was expressed as a peak (a.u.).

A.

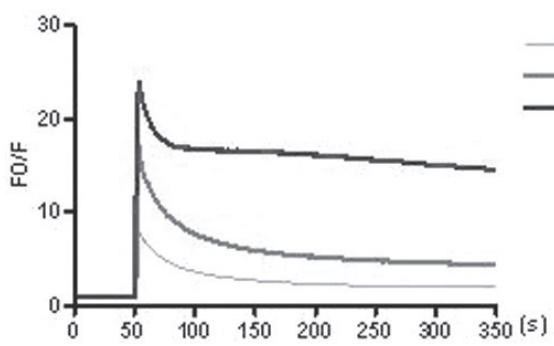

B.

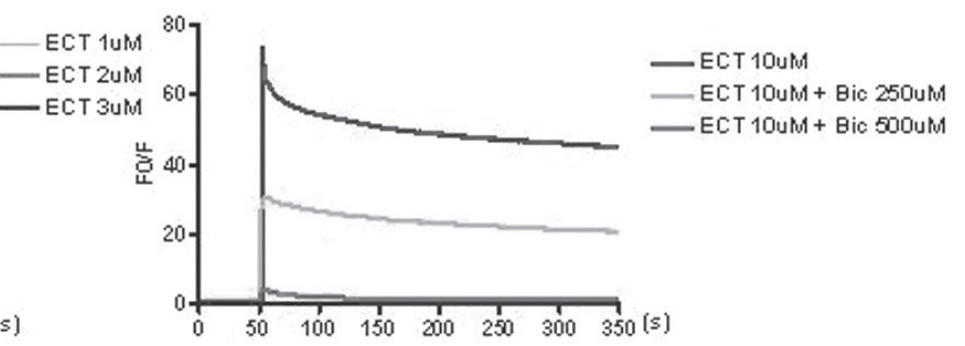

Fig. 8. Effects of $E C T$ on $\left[\mathrm{Cl}^{-}\right] \mathrm{i}$ in neuroblastoma cells. Fluorescence was monitored in the excitation wavelength at 365 nm and the emission wavelength at $450 \mathrm{~nm}$ using the $\mathrm{Cl}^{-}$-sensitive indicator, $\mathrm{N}$-(6-methoxyquinolyl) acetoetylester (MQAE). Contents of influx $\mathrm{Cl}^{-}$ion was expressed as a peak (a.u.).

$\mathrm{kg}$ ). $A C$ reduced $C C_{50}$ and $P T Z$-induced seizure response in a dose-dependent manner. PTZ is an uncompetitive GABA receptor antagonist and strychnine is a glycine receptor antagonist (Takeuchi and Takeuchi, 1969). Although animal models based on PTZ have still been widely used for drug screening, the mechanism by which PTZ elicits its action has not been completely understood. One generally accepted mechanism by which PTZ exerts its action is by acting as an antagonist at the picrotoxin sensitive site of GABAA receptor complex (Ramanjaneyulu and Ticku, 1984). GABA is a principal inhibitory neurotransmitter in the mammalian central nervous system, producing inhibitory post-synaptic potentials in both feedforward and feedback circuits. Impairment of GABA-mediated inhibitory circuits has been implicated in different forms of epilepsy in experimental animal models and in human studies (Hansen et al., 2004; Morimoto et al., 2004).

The result of inhibiting PTZ-induced seizure indicate that the effects of $A C$ may be related to the enhancement of GABA function in the brain, whereas failure to inhibit strychnineinduced seizures when $100 \mathrm{mg} / \mathrm{kg}$ or $200 \mathrm{mg} / \mathrm{kg}$ of $A C$ was treated indicates that $A C$ does not have much constituents having effects on the glycine-related response in the spinal cord (Takeuchi and Takeuchi, 1969). This suggests that the anticonvulsant effect of AC is more related with the $\mathrm{Cl}^{-}$channel of the GABA: benzodiazepine (BDZ) receptor complex. However, as AC also inhibited strychnine-induced seizures at its high dose, it indicates that its anticonvulsant effect is not solely related to GABAergic neuron.

The anticonvulsant effect of BDZ agonist is due to its fa- cilitating effect on the inhibitory GABAergic neurotransmission in the central nervous system. The mechanism of this facilitating action of BDZ agonist is via the activation of the BDZ binding site on the GABAA receptor to increase the frequency of the chloride $\left(\mathrm{Cl}^{-}\right)$channel openings in response to a given concentration of GABA (Study and Barker, 1982). Therefore, the present study investigated the $\mathrm{Cl}^{-}$influx using the neuroblastoma cells. Bicuculline, GABA antagonists, inhibited the $\mathrm{Cl}^{-}$influx induced by $A C$ in a dose-dependent manner. This suggests that the anticonvulsant effect of $A C$ was mediated by enhancing the GABA function.

$E C T$, the main constituent of $A C$, significantly increased the $\mathrm{CC}_{50}$ and $\mathrm{Cl}^{-}$influx in a dose-dependent manner. Like AC, bicuculline also inhibited $\mathrm{Cl}^{-}$influx induced by ECT. This similar activities indicate that ECT also exerts anticonvulsant effect through the GABAergic neuron. In the course of our study, separating constituents from ethanol fraction of $A C$, we found out the ECT accounts for $2 \%$ among the constituents and only ECT exhibited anticonvulsant effect through the GABAergic neuron. Thus we concluded that the GABAergic neuronal anticonvulsant effect of $A C$ is due to ECT.

This study demonstrated that AC treatment resulted in a dose-dependent increase of the electroshock seizure threshold. Unlike diazepam, AC did not cause sedation and myorelaxation in locomotor activity and the rota-rod test. These results indicate that the anticonvulsant effect of $A C$ cannot be attributed only by interaction with GABA function, although the action of $A C$ on the GABA receptor complex contributes to the anticonvulsant effect of AC. Besides, when highest dose (400 
$\mathrm{mg} / \mathrm{kg}$ ) of $\mathrm{AC}$ was treated, $\mathrm{AC}$ also decreased the seizure response induced by strychnine. Although ECT exerts similar activities with $A C$, the GABAergic anticonvulsant effect, there may be still other kinds of constituents which exert anticonvulsant effect through the non-GABAergic neuron. Further studies are required to find out which constituent is responsible for the non-GABAergic anticonvulsant effect.

In conclusion, AC possesses anticonvulsant effect which can be attributed to the potentiation of the activity of GABA and its activity is mediated by ECT. However, more studies are required to find out any other constituents which exerts other mechanisms of anticonvulsant activity.

\section{ACKNOWLEDGMENTS}

This research was supported by grant No. 09112 Hanyakjae 890 from SHM program of Korean Food and Drug Administration.

\section{REFERENCES}

Browning, R. A., Wang, C., Lanker, M. L. and Jobe, P. C. (1990) Electroshock-and pentylenetetrazol-induced seizures in genetically epilepsy-prone rats (GEPRs): differences in threshold and pattern. Epilepsy Res. 6, 1-11.

Eisenberg, D. M., Davis, R. B., Ettner, S. L., Appel, S., Wilkey, S., van Rompay, M. and Kessler, R. C. (1998). Trends in alternative medicine use in the United States, 1990-1997: results of a follow-up national survey. J . Am. Med. Assoc. 280, 1569-1575.

Egan, D., O’Kennedy, R., Moran, E., Cox, D., Prosser, E. and Thornes, R. D. (1990) The pharmacology, metabolism, analysis and applications of coumarin and coumarin-related compounds. Drug Metab. Rev. 22, 503-529

Farkas, S., Berzsenyi, P., Kárpáti, E., Kocsis, P. and Tarnawa, I. (2005) Simple pharmacological test battery to assess efficacy and side effect profile of centrally acting muscle relaxant drugs. J. Pharmacol. Toxicol. Methods 52, 264-273.

Gidal, B. E., Sheth, R. D., Bainbridge, J., Ramsay, E., Welty, T. E., Weatherford, K. J., Gilliam, F., Gallo, B. V., Alldredge, B. K., Montouris, G. D., Belden, D. S. and Lenners, A. (1999) Alternative medicine (AM) use in epilepsy: results of a national, multicenter survey. Epilepsia 40(Suppl 7), 107-108.

Hansen, S. L. and Sperling, B., Sanchez, C. (2004) Anticonvulsant and antiepileptogenic effect of GABA receptor ligands in pentylenetetrazole-kindled mice. Prog. Neuro-Psychopharmacol. Biol. Psychiatry 28, 105-113.

Kim, M. K., Yu, G. Y., Tan-Lee, B. S., Oh, H. J., Dong, K. W., Jeong, S. H., Han, S. W. and Cheong, J. H., (2003). Anti-stress effect of Pyroligneous liquid in SD rats and ICR mice. J. Appl. Pharmacol. 11, 249-256.

Lee, G. S., Choi, J. Y., Ko, H. S., Tan-Lee, B. S., Yu, G. Y., Park, H. G., Kim, M. K., Ryu, J. H., Jung, I. K. and Cheong, J. H. (2006) Stressreducing effects of brown rice Koji. Food Sci. Biotechnol. 15, 63-69.

Lin, W. L., Wang, C. J., Tsai, Y. Y., Liu, C. L., Hwang, J. M. and Tseng, T. H. (2000) Inhibotory effect of esculetin on oxidative damage induced by t-butyl hydroperoxide in rat liver. Arch. Toxicol. 74, 467472
Litchfield, Jr, J.T. and Wilcoxon, F. (1949) A simplified method of evaluating dose effect experiments. J. Pharmacol. Exp. Ther. 96, 99-113.

Morimoto, K., Fahnestock,M. and Racine, R. J. (2004) Kindling and status epilepticus models of epilepsy: rewiring the brain. Prog. Neurobiol. 73, 1-60.

Ngo Bum, E. N., Schmutz, M., Meyer, C., Rakotonirina, A., Rakotonirina, S. V., Olpe, H. R. and Herrling, P. (2001) Anticonvulsant properties of the methanolic extract of Cyprus articulatus (Cyperaceae). J. Ethnopharmacol. 76, 145-150.

Noldus, L. P. J. J., Spink, A. J. and Tegelenbosch, A. J. (2001) Ethovision: a versatile video tracking system for automation of behavioral experiments. Behav. Res. Meth. Instrum. Comput. 33, 398-414.

Novack, G. D., Starkand, L. G. and Peterson, S. L. (1978) Anticonvulsant effects of benzhydryl piperazines on pentylenetetrazol-induced seizures in mice. Neuropharmacology 17(Suppl8), 659-663.

Obniska, J., Kołaczkowski, M., Bojarski, A. J. and Duszyńska, B. (2006) Synthesis, anticonvulsantactivityand5-HT1A,5-HT2Areceptoraffinityofnew $\mathrm{N}$-[(4-arylpiperazin-1-yl)-alkyl]derivativesof2-azaspiro[4.4]nonaneand[4.5]decane-1,3-dione. Eur. J. Med. Chem. 41 (Suppl 7), 874-881.

Okada, Y., Miyauchi, N., Suzuki, K., Kobayashi, T., Tsutsui, C., Mayuzumi, K., Nishibe, S. and Okuyama, T. (1995) Search for naturally occurring substances to prevent the complications of diabetes. II. Inhibitory effect of coumarin and flavonoid derivatives on bovine lens aldose reductase and rabbit platelet aggregation. Chem. Pharm. Bull. 43, 1385-1387.

Park, H. G., Yoon, S. Y., Choi, J. Y., Lee, G. S., Choi, J. H., Shin, C. Y., Son, K. H., Lee, Y. S., Kim, K. W., Ryu, J. H., Ko, K. H. and Cheon, J. H. (2007) Anticonvulsant effect of wogonin isolated from Scutellaria bacalenesis. Eur. J. Pharmacol. 574, 112-119.

Paya, M., Halliwell, B. and Hoult, J. R. S. (1992) Interactions of series of coumarins with reactive oxygen species: Scavenging of superoxide, hypochlorous acid and hydroxyl radicals. Biochem. Pharmacol. 44, 205-214.

Poole, K., Moran, N., Bell, G., Solomon, J., Kendall, S., McCarthy, M., McCormickc, D., Nashefd, L., Johnsone, A., Sandera, J. and Shorvon, S. (2000) Patients' perspectives on services for epilepsy: a survey of patient satisfaction, preferences and information provision in 2394 people with epilepsy. Seizure 9, 551-558.

Ramanjaneyulu, R. and Ticku, M. K. (1984) İnteractionsofpentameth ylenetetrazoleandtetrazoleanalogueswiththepicrotoxininsiteoftheb enzodiazepine-GABAreceptor-ionophorecomplex. Eur. J. Pharmacol. 98, 337-345.

Sander, J. W. (2003) The epidemiology of epilepsy revisited. Curr. Opin. Neurol. 16, 165-170.

Shumaker, H., Amlal, H., Frizzell, R., C. D. Jr. and Soleimani, M. (1999) CFTR drives $\mathrm{Na}+-\mathrm{nHCO} 3-$ cotransportinpancreaticductcells: abasisfordefectiveHCO3-secretionin CF. AM. J. Physiol. 276, C16-C25.

Study, R. E. and Barker, J. L. (1982) Cellular mechanisms of benzodiazepine action. J. Am. Med. Assoc. 247, 2147-2151.

Takeuchi, A. and Takeuchi, N. (1969) A study of the action of picrotoxin on the inhibitory neuromuscular junction in crayfish. J. Physiol. 205, 377-391.

Tang, W. and Eisenbrand, G. (1992) Chinese drugs of plant origin: chemistry, pharmacology, and use in traditional and modern medicine. p.179. Springer-Verlag, Heidelberg, New York.

Verkman, A. S., Sellers, M. C., Chao, A. C., Leung, T. and Ketcham, R. (1989) Synthesis and characterization of improved chloridesensitive fluorescent indicators for biological applications. Anal. Biochem. 178, 355-361.

West, M. R. and Molloy, C. R. (1996) A microplate assay measuring chloride ion channel activity. Anal. Biochem. 241, 51-58. 